\title{
Travesses d'aigua al terme de Borriana: de la toponímia a la hidronímia
}

\author{
JoAN R. Monferrer DAUdí (joan.monferrer@uji.es) \\ Universitat Jaume I
}

\section{Introducció}

Conèixer el nostre entorn és, potser, un dels primers reptes que ens hauríem de plantejar com a ciutadans, com a aprenents i com a ensenyants. Sobretot, davant d'un món globalitzat en què tenen més importància les coses d'altri que no les nostres, pel simple fet de pertànyer a una societat i a una cultura minoritzada que no té visibilitat. De què ens serveix conèixer accidents geogràfics d'arreu del món si no coneixem el nostre terme. Està molt bé visitar la Patagònia o les cascades del Niàgara, però encara està millor visitar les goles del Millars, la Bota o l'Estany de la Vila, que els tenim a casa nostra i són nostres, o saber, simplement, que el Millars desemboca a Borriana.

Tot i que aquest article tracta aspectes referits a la toponímia del terme de Borriana, ens centrarem, principalment, en la hidronímia o nom de les séquies, però també farem referència a algunes partides o camins del terme de Borriana, pel fet que no podem separar les referències toponímiques en la hidronímia. No entrarem en altres aspectes, com ara el dret i les particions o repartiment de l'aigua del Millars entre els pobles de la Plana, ni sobre qualsevol altre aspecte que no tinga una relació directa amb el motiu d'aquest estudi-assaig. Així, doncs, nosaltres recollirem l'aigua des del pantanet de Santa Quitèria i l'acompanyarem fins a la mar, tot fent una passejada per les séquies i braçals del terme de Borriana.

La hidronímia local denota certament una llarga història i tradició en el sistema de reg del terme de Borriana i així ho demostren algunes formes arcaiques que trobem en el nom de les séquies més importants i en els noms comuns de la major part del sistema de reg i d'algunes séquies terminals. Per una altra banda, una complicada xarxa de canals per fer arribar l'aigua a cada racó del terme municipal des de fa molts segles fa del nostre sistema de reg un sistema ric i complex, també en el nom de les séquies.

Aquest treball, i d'altres que arribaran posteriorment, sobre la toponímia del terme de Borriana, són un homenatge a mon pare, Pepe Monferrer, al meu avi, Lleonardet Daudí, i a tots els meus avantpassats que han treballat i han viscut de la terra al llarg de moltes generacions. Alhora, vol ser també un homenatge al meu poble i a la seua gent, amb l'estudi i l'anàlisi de les seues arrels, perquè qui no coneix i reconeix la seua història i les seues arrels difícilment podrà fornir un futur profitós.

Finalment, vull agrair la colllaboració de les persones lligades al món agrari local i del Sindicat de Regs que m'han ajudat a resoldre diversos dubtes relacionats amb l'estudi toponímic, especialment, Jorge Blasco. També voldria agrair la colllaboració desinteressada d'aquelles persones que m'han cedit part del seu temps per aclarir alguns dubtes. 


\section{Riu avall}

«Tradicionalment, tota l'aigua utilitzada per la Comunitat -de regants de Borriana- era derivada del Millars per mitjà de l'assut de Burriana. En l'actualitat, l'assut continua fent eixa funció, però el més habitual és que l'aigua arribe a l'assut per un canal -canal cobert conegut com canal Vicent Serra- que la porta del pantanet de Santa Quitèria, un xicotet embassament de regulació de $200.000 \mathrm{~m} 3$, en funcionament des de 1983, que acumula l'aigua desembassada del Sitjar i permet que Borriana, Castelló i Almassora no hagen de regar de nit.» (Garrido i Vicent, 2010: 135)

Ja tenim l'aigua a l'assut de Borriana, en terme de Vila-real, i des d'ací començarem la descripció toponímica de les séquies que escamparan l'aigua pel nostre terme. L'assut acumula l'aigua que li arriba pel riu i pel canal que ve de Santa Quitèria. A més de la resclosa, les installlacions consten d'una vivenda per a l'assuter-actualment, amb l'automatització de les comportes de l'assut, ha desaparegut la figura d'assuter i és un zelador qui fa alguna de les funcions que feia l'assuter-i d'una caseta de comportes, des d'on es controlaven les comportes que regulen l'abastiment d'aigües als termes de Borriana i Nules a través de la séquia de Borriana o séquia Major.

«Després de l'assut, la séquia de Borriana transcorre paral-lela al Millars, pel seu marge dret, durant poc més de dos kilòmetres. En aquest tram que transcorre pel terme municipal de Vila-real i va ser revestit l'any 1931, no existeix la possibilitat de regar, perquè va encaixat. Quan arriba al terme municipal de Borriana ja ha guanyat altura suficient per a poder abandonar el riu, fa un gir de $90^{\circ}$ i pren la direcció NE-SW.» (Garrido i Vicent, 2010: 147)

Abans d'arribar al partidor, ja en terme de Borriana a vora carretera d'Almassora, la séquia Major fa la primera cessió d'aigua a través de l'ull de les Forques que forneix d'aigua dos braços, la Forca de Vora Riu i la Forca de Vora Camí, els sobrants vessen a través d'un derramador a la séquia de la Moleta i a la séquia del Molinou.

A un centenar de metres de l'ull de les Forques, la séquia Major es divideix en tres braços en el partidor Major: la séquia Jussana ('la de baix') que rega el terme de Borriana del riu de Millars al riu Sec, la séquia Sobirana ('la de dalt') que rega la resta de terme, des del riu Sec fins al terme de Nules, i la séquia de Nules que s'endú l'aigua per al reg del terme de Nules.

\subsection{La Jussana}

La séquia Jussana té quatre drets o regs: 1. Molinou, 2. Terços de Matella i de Palau, 3. Matella i 4. Palau. En passar el partidor major, molt a prop, la séquia Jussana es divideix en la séquia del Molinou i la séquia comuna de Palau i Matella.

- La séquia de Molinou, per la seua banda, té quatre drets o regs: 1. parada de Miralles, 2. presa de Serra, 3. reg de dia i 4. reg de nit. La parada de Miralles rega les seues terres afectades. La presa de Serra (o séquia de Santa Bàrbara) distribueix l'aigua entre el braçal de la Moleta, el braç de Serra, que alhora les distribueix entre el braçal de Serra i la fillola de Serra (o Pardaler), i el braç de Vinyes, que més endavant se subdivideix en el bracet de Vinyes i el braçal de Vinyes. El reg de dia repartia l'aigua de la séquia del Molinou des de l'exida del sol fins a la posta 
entre els braçals: Terços del Molinou, les tres Filloles del Molinou (1. fillola del Masquemado, 2. fillola del mig i 3. fillola del camí de la Mar de Vila-real) i les filloles de Mitjà del Molinou (1. fillola del Llargo, 2. fillola de Guernieta, 3. fillola de Sorongo, 4. fillola de Fernando Badia, 5. ull de la Torre d'Uclés (que se subdivideix en el braçal del Gual Reial i la séquia de la Torre d'Uclés), 6. fillola del Tender, 7. fillola de Peixeta, 8. fillola de Borriolet 9. ull de la Figuereta, 10. ull de l'Estudiant, 11. fillola del Racó). El reg de nit repartia l'aigua de la séquia del Molinou des de la posta del sol fins a l'exida del sol pel mateix partidor entre les filloles del braçal Mitjà de Molinou següents: 12. filloleta de Monsonís, 13. filloleta de la Camiseta, 14. filloleta de Ríos, 15 . filloleta de Montoia, 16. filloleta de la Granja, 17. fillola del Català, 18. filloleta de Boix, 19. fillola d'Hipòlit Montoia, 20. filloleta de les Palmeretes, 21. filloleta de la Pajarona, 22. ullet del Palomar, 23. fillola dels Frares, 24. fillola dels Corders, 25. fillola del Molí de l'Arròs, 26. alters de la Granja i 27. alter de Monsonís). En l'actualitat, amb la construcció del pantanet, ha desaparegut el reg de nit i ara només es rega de dia, tant les zones que es regaven pel reg de dia com les que es regaven pel reg de nit.

- El segon dret o reg de la séquia Jussana és per al tram comú de la séquia de Palau i Matella, que reguen els terços de Matella i Palau; a través de dos ulls s'abasteixen d'aigua les séquies del primer terç de Palau i Matella i el segon terç de Palau i Matella, el reg és de dia i no s'obri el segon ull fins que no ha acabat el primer.

- El tercer dret o reg de la séquia Jussana és per a la séquia de Matella. Després del tram comú de Palau i Matella, la séquia de Palau se separa de la de Matella a través d'un partidor. Des d'ací, la séquia de Matella rega les terres fins a la mar a través d'una ramificació de séquies que inclou les filloles següents: 1. fillola del Racó, 2. fillola del camí la Mar de Vila-real, 3. fillola dels Alters, 4. fillola Sorda, 5. fillola de Soriano, 6. fillola de la Torre, 7. fillola de Marlaco, 8. fillola dels Ullets, 9. fillola del Volantí, 10. ullet del Soldat, 11. portell dels alters de Lozano, 12. portell dels alters de Montoliu, 13. fillola de les Secretàries, 14. fillola de Santa Pau, 15. fillola dels Tumbets, 16. comunet de Sales, 17. ullet de Palomar, 18. filloleta del Cabeçol, 19. fillola de Batxitxa, 20. alters d'Eulàlia Monsonís, 21. alters de Perelló, 22. fillola de Monsonís i 23. fillola dels Moliners.

- El quart dret o reg de la séquia Jussana és per a la séquia de Palau. Com hem dit adés, les séquies del Palau i Matella se separen per un partidor després del tram comú. Té reg de dia i reg de nit, tot i que en l'actualitat ambdós regs es fan de dia. El reg de dia es divideix en quatre torns. El primer torn comença en el camí de la Mar de Vilareal i acaba en el camí vell de Vila-real, i abasteix les filloles següents: 1. fillola de Messeguer, 2. fillola del Tongo, 3. fillola del Mono, 4. fillola de la Carrasqueta, 5. fillola del Pardaler, 6. ull del Cedre, 7. fillola d'Oliveros, 8. fillola de les Serafines (o de Ríos), 9. fillola de Vergadà, 10. ullet de Font, 11. fillola de Victorianet, 12. fillola de Serreta (o de la Pardalera) i 13. alter de Franch. El segon torn abasteix els ulls següents: 1. ull del Magraner, 2. ull del Tol, 3. ull del Pont. El tercer torn rega a través de l'ull del Rajolar, l'ull del Cementeri i la fillola de l'Almenara. El quart torn distribueix l'aigua, primer, a la parada del Riu i, després, a través del braç de Vora riu a 1. la parada de Ríos, 2. la parada de Montsó, 3. fillola de Montoliu, 
4. fillola del Notari, 5. fillola de Ximet el Ros, 6. fillola del Forn de la Calç i 7. fillola del camí la Clossa; i a través de la fillola de Baix reparteix a 1. la fillola de Llopis de Burgada, 2. fillola del Pènic i 3. ullet de Pere Blai. El reg de nit arreplega l'aigua de la séquia del Palau i la du a l'ull del Baró, que desaigua al riu després del pont del camí de les Salines.

\subsection{La Sobirana}

Després del partidor major que separa la séquia Jussana de la Sobirana, la séquia Sobirana té quatre comportes installades en la casa de comportes a vora carretera d'Almassora. De les quatre, les dos de baix són per a la séquia Sobirana i les dos de dalt per a la séquia de Nules. La séquia Sobirana també es coneix com la séquia de la Tanda, potser perquè fins a finals del segle XIX era la séquia que abastia el terme de Borriana, al sud del riu Sec, i el terme de Nules, per tant, donava tanda (torn d'aigua) alternativament a Borriana dotze dies i a Nules sis dies, quan Nules no tenia séquia pròpia. Actualment, com hem vist més amunt, la Sobirana només rega la zona sud del terme de Borriana, des del riu Sec fins a la ratlla de Nules.

Per a l'aprofitament del torn de tanda de Borriana (dotze dies) s'establien dos torns: la tanda d'Horta (nou dies) i la tanda de Cap de terme (tres dies). La tanda d'Horta rega des del primer torn del Mitjà de la Tanda fins a l'ull del Pont. La tanda de Cap de terme rega des de l'ull del Caràmit fins al desaigüe del Fleix.

- En la tanda d'Horta s'inclouen dos drets o regs: el del Mitjà i el d'Horta.

El Mitjà de la Tanda rega en dos torns, el primer torn inclou: 1. portell de Tomaques, 2. ull del Manyà, 3. portell de Ribera, 4. portell de Ramos, 5. portell de l'Homenet, 6. ull del Tongo, 7. portell de Carda, 8. ull de Llop, 9. portell de Llop, 10. ull de Medrano, 11. portell de la Bessona, 12. portell del Molí Cremat. El segon torn distribueix a: 13. ull del camí de Vila-real, 14. ull de Calero, 15. ull de la Muda, 16. ull de l'Olivereta, 17. ull del Gitano, 18. ull de Pont Corrent, 19. ull del Cedre, 20. portell de Mallola-1, 21. portell de Mestre, 22. portell de Ros, 23. ull de Pixagorres, 24. portell de Mallola-2, 25. portell de Quaresma, 26. portell de Candau, 27. ull de Campets, 28. ull del Toll, 29. ull de Panissares (o de la Sanguina), 30. portell del Molí de Palos.

El dret o reg d'Horta reparteix l'aigua a: 1. ull del Molí, 2. ull de Canyaret, 3. ull de l'Ereta, 4. ull del Secanet, 5. ull de Tirado, 6. ull del Braç, que rega l'Horta del Braç, Carabona i la Regenta, 7. ull d'Hortolans, 8. ull de Nicolau, 9. portell de l'Hospital (o Farinera), 10. ull de la Vila, 11. ulls del Finello, que assorteix d'aigua tres braçals, 11a. braçal del Convent, 11b. braçal del Mig i 11c. braçal de l'Eccehomo, 12. ull de Vinaralls, 13. ull de la Bosca, 14. ull del Polaco, 15 ull del Rovellat, amb dos braçals Eccehomo i Ponent, 16. ull del Pont.

- La tanda de Cap de Terme abasteix d'aigua 10.229 fanecades i 90 braces a través de diversos ulls. Comença per l'ull del Caràmit que té un tram comú anomenat Caràmit comú d'on naixen l'ull de la Figuereta, ull de Pere Monsonís, ullet de González (o de Burgaleta) i la fillola de Bessa. Més endavant, en arribar al camí de les Tancades, es divideix en dos braçals, primer braç del Caràmit amb les filloles: fillola del Toro, 
fillola de Pepet d'Aín, fillola del Racó, fillola de Pere Monsonís, fillola dels Petits i fillola de Carbonell, desaigua a la mar per la gola del Caràmit. El segon braç del Caràmit té les filloles: fillola de Montoliu, fillola del Calb i fillola de Carles i Pepeta, desaigua al Rajolí de la senda de l'Ullal.

Després de l'ull del Caràmit, en la tanda de Cap de Terme trobarem l'ull del Marsanac i després l'ull de Llombai que amb 33 filloles «és la més llarga de les séquies secundàries del terme de Borriana, amb 4.610 m» (Garrido i Vicent, 2010: 307) entre les filloles trobem: la fillola de Peret, fillola de Vila, fillola de Marcelo, fillola de Barraques, fillola de Sardina, fillola de Varella, fillola de Fogassa, fillola del Millonari, fillola de Cervereta, fillola del marge de Conde, fillola de la Vela, fillola del Surdo, fillola del Mecànic, fillola de la Redona, fillola de Sabre, fillola del Coso, fillola de Botero, fillola de la Miralles, fillola de Teodoro, fillola de Patricio, fillola de la Canya, fillola de Monsonís, fillola de Mingarro-1, fillola de Mingarro-2, fillola de la Gilda i fillola del Saurino.

Més endavant tenim l'ull del Fuster, que travessa l'actual carretera de Nules i es divideix en tres braçals: la fillola de la Gallina, la fillola del Mig i la séquia de l'ull del Fuster. Després de l'ull de Fuster, en la tanda de Cap de Terme trobarem l'ull del Fleix (freixe). El primer tram, Fleix comú, rega els sis marges: marge de les Alqueries del Ferrer, marge del Xop, marge de Monfort, marge del Rajolar, marge del Finestró, marge del Garroferar. Més endavant, la séquia de l'ull del Fleix es divideix en dos braçals per un partidor que comença amb un tallamar. Fleix 1r braçal, el de dalt, és la séquia Mitjana i el Fleix 2n braçal és la fillola de Benitxola i assorteix d'aigua el marge d'Elies i el marge del Palmerar. La tanda de Cap de Terme encara abastirà l'ull de Carabona, ull de la Conillera, ull de Carronya, ull del Trencat (o del Rajolar), ull del Canó, ull de la Caseta i ull de Vareta.

Pel que fa a les goles, eixides de les séquies per a desaiguar a la mar, a més de les goles del Millars, trobem la gola de l'estany Llarguer, gola de Mossèn Vicent, gola del Marjalet, gola de l'estanyet de Colombrí, gola de l'ull de la Vila, gola del Rajolí de la Malva-rosa, gola del segon braçal del Finello, gola del Rovellat, segon braçal, gola de Barruguer, gola del Caràmit, i la gola Nova.

\section{La hidronímia}

La hidronímia forma part de la toponímia, si bé fa referència al nom de les séquies i, en general, de les conduccions d'aigua. Per tant, farem servir el terme hidronímia, però també farem servir el terme toponímia com a hiperònim d'hidronímia o quan fem referència $a$ topònims que designen camins o partides del terme.

El nom de les séquies, igual com la toponímia rural o urbana, està format per un nom comú que defineix el tipus de canalització que és (més important o més gran i més menuda o ramals mitjans o finals) i per un nom propi que la identifica, independentment de la procedència del nom. Per a explicar el nom de l'entramat del sistema de reg del terme de Borriana, parlarem primer del nom comú o genèric que solem trobar en la part inicial de l'hidrònim, i després classificarem els noms propis segons les característiques que permeten agrupar-los. 


\subsection{El nom comú}

Considerem com a nom comú la primera part de l'hidrònim que fa referència al tipus de canalització o jerarquia, segons el nivell de ramificació, o a la manera de recollir l'aigua de la séquia anterior. La primera séquia que trobem és la séquia Major o séquia de Borriana, que en arribar al partidor principal distribueix les aigües de la séquia Major entre la séquia Jussana i la séquia Sobirana, que travessarà la casa de comportes per a distribuir l'aigua de la Sobirana entre la séquia Sobirana o la Tanda i la séquia de Nules.

Així, parlem de séquia per a referir-nos a les canalitzacions principals de la xarxa de reg. La resta de séquies que naixen a partir de la ramificació de les principals usaran altres noms i només faran servir el nom 'séquia' en sentit genèric, com a sinònim de canalització o rec. Les primeres divisions se solen anomenar braç o braçal, i les segones fillola. Per tant, de la séquia naix un braç (o braçal) i del braçal, filloles. En el cas de les séquies del Molinou, de Palau i de Matella, s'anomenen séquies perquè substitueixen ben prompte el topònim de la séquia Jussana.

El cas d'ull i portell està relacionat amb la manera com es desvia l'aigua des de la séquia per on corre a una altra de nivell inferior per ramificació. L'aigua corre pel caixer de la séquia, es considera caixer el llit de la séquia i, també, cada paret lateral. L'ull és un forat, més o menys redó, de mida variable segons el cabal que se li dona a la séquia que naix de l'ull, fet originàriament en una llosa de pedra situada en la part baixa del caixer lateral per on volem desviar l'aigua. Antigament, alguns, estaven folrats de bronze per evitar-ne el desgast que podia produir-se que, alhora, provocaria un augment del cabal d'aigua. El portell és una obertura rectangular feta a la part superior del caixer i tancada amb una llosa d'obra que, de vegades, se substitueix per una planxa de ferro i actualment també de fibra.

Un gual és un pas d'aigua amb poca profunditat per on es pot travessar sense dificultat. També es considera gual la séquia o conducció on desguassen les escorrenties del reg d'un determinat tros. La palafanga, per la seua banda, és una canalització o séquia per on s'escorre l'aigua d'una zona d'aiguamolls; a Borriana trobem aquests topònims bàsicament a la zona del camí del Marjalet pròxima a la mar. Sequiol, d'acord amb la definició dels diccionaris, és un diminutiu de séquia, per tant, una séquia menuda; però, a Borriana, fem servir sequiol amb el sentit de 'palafanga' per a les canalitzacions de la zona d'aiguamolls que coneixem com la marjal, al sud-est del terme municipal.

Convé puntualitzar, en referència a les definicions que hem reproduït en el glossari, alguns noms comuns que apareixen en les denominacions generals de les séquies, com ara, l'adjectiu comú, que s'empra per a denominar els trams compartits per dues séquies abans de dividir-se. El marge fa referència als límits d'una propietat o d'un espai físic, però també és el nom que reben les filloles que hi ha per la zona del camí del Marge. Un terç és una séquia, o porció de reg, que distribueix la tercera part de l'aigua que li correspon com a dret o reg del total de la que du la séquia que l'abasteix. Un derramador és una obertura en la part superior del caixer lateral d'una séquia que permet abocar-ne l'aigua sobrant en una altra per tal d'aprofitar-la en cas d'excés. Les escorrenties són les aigües que es filtren i vessen a un rec, gual o desaigüe, que les arreplega i les canalitza per a reaprofitar-les o per a abocar-les al riu o a la mar. 
El cas de la Bota és, si més no, un cas curiós, perquè es tracta d'una solució d'enginyeria per a travessar el riu Sec amb un sistema semblant a un sifó, en el qual la séquia Sobirana passa a l'altra banda de riu soterrada, i en la part del llit del riu queda com si fora una cisterna (o bota). Antigament, el pas del riu es feia en superfície i cada volta que venia una riuada calia reparar la séquia Sobirana, una cosa semblant al que avui en dia passa amb la passarel-la de l'Estany de la Vila o Clot de la Mare de Déu.

Cal distingir la diferència de sentit entre parada i presa. La primera, parada, suposa la interrupció del curs de la séquia per tal de desviar-la a una altra séquia, habitualment amb posts de fusta o fibra. La presa, per contra, suposa una retenció de l'aigua en un punt de més capacitat per a, posteriorment, distribuir-la segons els drets i les necessitats.

Els alters són zones del terme més altes que requereixen una atenció especial perquè el sistema de reg tradicional a Borriana és el reg a manta, que inunda els horts i funciona per decantació, del cap de dalt de l'hort al cap de baix, on s'escorren els sobrants. Tot i que el terme de Borriana sembla pla, en realitat no ho és, i cal fer arribar l'aigua a tot el terme, als alters també. Per cert, quan parlem de dalt i baix, no parlem de nord i sud, sinó de més allunyat de la mar (dalt) i de més a prop de la mar (baix); així, una persona que va del Grau a Borriana, 'puja al poble', i una que va de Borriana al Grau, 'baixa a la mar'.

Finalment, les goles són les eixides de les séquies que desguassen a la mar, bé amb aigua sobrant del reg o bé amb aigua de pluja, especialment quan les pluges són importants, per això convé tindre-les sempre ben netes i no tapar-ne cap, com ja s'ha fet en algun cas. El Rajolí és un cas ben curiós de séquia, semblant a un sequiol o palafanga; està situat en paral·lel i molt a prop de la mar en les zones d'aiguamolls, les marjals, el port i la Malvarosa i en la partida de Sant Gregori. La funció principal del Rajolí és mantindre un nivell d'aigua, freàtic o en superfície, adequat als aiguamolls, recollir les escorrenties i vessar-ne l'excés a la mar a través de les goles.

En aquest apartat també convé fer referència a l'ús del diminutiu per a indicar jerarquia o grandària, així tenim fillola $>$ filloleta, braç $>$ braçal $>$ bracet, ull $>$ ullet, comú $>$ comunet, Rajolí>Rajolinet, entre d'altres. Cal indicar que fillola (fill) i rajolí (raig) ja són diminutius, però les paraules de què depenen tenen un sentit diferent. En el cas de séquia i sequiol, com ja hem vist, tot i que la segona és inicialment un diminutiu de la primera, nosaltres la usem amb un sentit diferent ('palafanga').

\subsection{El nom propi}

El nom propi és la part de l'hidrònim que identifica el lloc on se situa la séquia o conducció del reg. Les principals s’identifiquen per l'adjectiu, Major, que indica el rang de principal, o pel topònim del poble, també anomenada séquia de Borriana perquè du l'aigua que rega tot el terme, igual com la séquia de Nules és la que du l'aigua al terme de Nules. En el segon nivell, les séquies principals es defineixen per dos adverbis de lloc habituals en la llengua antiga, però poc freqüents en l'actualitat, senyal de l'antiguitat del sistema de reg de Borriana: la séquia Sobirana, la séquia de dalt, i la séquia Jussana, la séquia de baix. En el partidor principal, la séquia que està més a prop de la mar és la séquia Jussana, 'la séquia de baix', que rega el terme 
de Borriana des del Millars fins al riu Sec de Betxí, i la séquia que està al costat més allunyat de la mar és la séquia Sobirana, 'la séquia de dalt', que rega el terme des del riu Sec fins al terme de Nules.

En aquest punt voldríem remarcar l'ús del nom Tanda en substitució de Sobirana. La paraula 'tanda' és sinònima de 'torn', per tant, aplicada a l'agricultura significa 'torn de regada'. La séquia Sobirana, durant molts segles, ha distribuït l'aigua entre la part sud del terme de Borriana 2/3 (12 dies de 18) i el terme de Nules 1/3 (6 dies de 18), de manera que alternava les tandes, la tanda de Borriana i la tanda de Nules. La séquia Sobirana és la séquia que duia les tandes, per tant, la séquia és coneguda principalment pel substantiu comú tanda, la Tanda, tot i que en els documents apareix bàsicament la denominació séquia Sobirana.

El complement del nom apareix especificant el nom propi quan cal distingir-ne més d'un, per exemple, en el cas de les Forques, en què en trobem dos: la Forca de Vora Riu i la Forca de Vora Camí.

Quan parlem de reg de dia i reg de nit són drets històrics de reg que només permeten regar o de dia o de nit. En l'actualitat, amb la construcció del pantanet de Santa Quitèria ja no hi ha reg de nit, tot el reg es fa de dia, i les séquies que tenien reg de nit es reguen, per torn, després de les que els corresponia reg de dia. Igualment, quan es parla de tanda d'Horta o reg d'Horta també són drets de reg que fan referència a la distribució de l'aigua i no a la toponímia de les séquies.

\section{Classificació del nom propi dels hidrònims}

A continuació, hem assajat una classificació dels noms propis dels hidrònims segons la procedència, tot i que en alguns casos els hem classificat en més d'un apartat per les seues característiques.

- Partides i camins del terme (topònim)

ull de les Forques, fillola del Masquemado, fillola del camí de la Mar de Vila-real, presa de Serra, braç de Serra, séquia de Santa Bàrbara, fillola de Serra, séquia de Matella, fillola de Santa Pau, ull del (camí del) Cedre, filloleta del Cabeçol, fillola del camí la Closa, ull del Caràmit, ull del camí de Vila-real, ull d'Hortolans, ull de la Vila, ulls del Finello, braçal de l'Eccehomo, ull de Vinaralls, ull de la Bosca, ull del Rovellat, Caràmit comú, primer braç del Caràmit, gola del Caràmit, segon braç del Caràmit, ull de Llombai, marge de les Alqueries del Ferrer, ull de Carabona, gola del Marjalet, gola de l'ull de la Vila, gola del segon braçal del Finello, gola del Rovellat.

- Llinatges, malnoms i renoms (antropònim, àlies, sobrenom, oficis o aficions)

- Llinatges i noms propis: parada de Miralles, braç de Vinyes, bracet de Vinyes, braçal de Vinyes, fillola de Guernieta, fillola de Fernando Badia, séquia de Palau, filloleta de Monsonís, filloleta de Ríos, filloleta de Montoia, fillola d'Hipòlit Montoia, filloleta de Boix, ullet de Palomar, alter de Monsonís, fillola de Soriano, portell dels alters de Lozano, portell dels alters de Montoliu, comunet de Sales, alters d'Eulàlia Monsonís, alters de Perelló, ull de Nicolau, fillola de Monsonís, fillola dels Moliners, fillola de Messeguer, fillola de les Serafines (o de Ríos), fillola de Vergadà, ullet de Font, fillola 
de Victorianet, fillola de Serreta, alter de Franch, ull del Tol, parada de Ríos, parada de Montsó, fillola de Montoliu, fillola de Ximet el Ros, fillola de Llopis de Burgada, ull de Tirado, fillola del Pènic, ullet de Pere Blai, portell de Ribera, portell de Ramos, portell de Carda, ull de Llop, portell de Llop, ull de Medrano, ull de Calero, portell de Mallola-1, portell de Mallola-2, portell de Mestre, portell de Ros, portell de Candau, ull del Marsanach, ull de Pere Monsonís, ullet de González, braçal del Gual del Real, fillola de Bessa, fillola de Pere Monsonís, fillola dels Petits, fillola de Carbonell, fillola de Montoliu, fillola de Carles i Pepeta, fillola de Peret, fillola de Vila, fillola de Marcelo, fillola de Varella, fillola de Cervereta, fillola del marge de Conde, fillola de la Miralles, fillola de Teodoro, fillola de Patricio, fillola de Monsonís, fillola de Mingarro-1, fillola de Mingarro-2, marge de Monfort, marge d'Elies, gola de mossèn Vicent, gola de Barruguer.

- Oficis o ocupacions: fillola del Tender, fillola dels Frares, fillola dels Corders, ullet del Soldat, fillola de les Secretàries, fillola d'Oliveros, fillola del Notari, ull del Manyà, portell de la Farinera, fillola del Mecànic, fillola de Botero, ull del Fuster.

- Malnoms, sobrenoms i renoms: fillola de Peixeta, fillola del Llargo, fillola de Sorongo, ull de l'Estudiant, filloleta de la Camiseta, filloleta de la Pajarona, fillola Sorda, fillola de Marlaco, fillola dels Tumbets, fillola de Batxitxa, fillola del Tongo, ull del Tongo, fillola del Mono, fillola de la Pardalera, portell de Tomaques, portell de l'Homenet, portell de la Bessona, ull de la Muda, ull del Gitano, ull de Pixagorres, portell de Quaresma, ull de Campets, ull de Panisares (o de la Sanguina), ull de Canyaret, portell de la Farinera, ull del Polaco, ullet de Burgaleta, fillola del Toro, fillola del Calb, fillola de Barraques, fillola de Sardina, fillola de Fogassa, fillola del Milionari, fillola del Surdo, fillola de la Redona, fillola de Sabre, fillola del Coso, fillola de la Gilda, fillola del Saurino, ull de Carronya, fillola de Benitxola.

- Gentilici: fillola de Borriolet, fillola del Català, fillola de Pepet d'Aín, ull dels Jueus.

- Punt de referència fitònim, orònim, zoònim, hidrònim, hagiotopònim...

- Fitònim o nom de planta

ull de la Figuereta, filloleta de les Palmeres, fillola de la Carrasqueta, ull del Cedre, ull del Magraner, desaigüe del Fleix (freixe), ull de l'Olivereta, ull de Canyaret, ull del Fleix, Fleix comú, marge del Xop, marge del Garroferar, Fleix 1r braçal, Fleix 2n braçal, marge del Palmerar, fillola de la canya.

- Orònim o nom elevació natural del terreny

fillola dels Alters, portell dels alters de Lozano, portell dels alters de Montoliu.

- Zoònim o nom d'animal

fillola de la Gallina, ull de la Conillera, gola de l'estanyet de Colombrí.

- Hidrònim o nom d'un curs d'aigua

fillola dels Ullets, parada del Riu, braç de Vorariu, ull del Pont (o dels Jueus), ull de Pont Corrent, ull del Toll, ull del Braç, l'horta del Braç, braçal del Gual del Real, gola de l'estany Llarguer, gola del Rajolí de la Malva-rosa.

- Hagiotopònim o nom de sant

pantanet de Santa Quitèria, séquia de Santa Bàrbara, fillola de Santa Pau, braçal de l'Eccehomo.

- Punt de referència locatiu 
fillola del Mig, Mitjà del Molinou, fillola del Racó, fillola de Baix, tanda de Cap de Terme, Mitjà de la Tanda, braçal del Mig, séquia Mitjana, partidor Alt.

- Nom de referència construcció o edifici

el Molinou, fillola del Masquemado, ull de la Torre d'Uclés, séquia de la Torre d'Uclés, filloleta de la Granja, fillola del Molí de l'Arròs, alters de la Granja, fillola de la Torre, ull del Pont, ull del Rajolar, ull del Cementeri, fillola de l'Almenara, fillola del Forn de la Calç, portell del Molí Cremat, portell del Molí de Palos, ull del Molí, portell de l'Hospital, braçal del Convent, marge del Rajolar, marge del Finestró, ull del Trencat (o del Rajolar), ull de la Caseta.

- Nom de referència agrícola

séquia la Moleta, ull de l'Ereta (d'era), ull del Secanet ('terra de secà').

- Altres (objectes, referències o característiques)

ull del Canó, ull de Vareta, gola Nova, fillola del Volantí, fillola de la Vela, ull del Baró.

\section{A tall de conclusió}

Aquest estudi o assaig inicia un camí que caldrà reprendre amb la finalitat d'ampliar-lo per tal d'incloure-hi la toponímia de camins i partides i, així, poder arribar a fer un estudi ampli sobre la toponímia general del terme de Borriana. Certament, existeix una relació directa entre el nom de moltes séquies i els noms de partides, camins i finques que donem nom a les séquies, bé perquè el curs de la séquia segueix el camí, passa per la partida $o$ rega una determinada finca el nom de la qual (nom, cognom o malnom del propietari) és la referència per a anomenar l'esmentada séquia. En aquest darrer cas volem fer notar la curta trajectòria temporal de l'hidrònim.

La complexitat i l'antiguitat de la xarxa de reg ens deixa noms comuns i noms propis que avui en dia són difícils de trobar o d'oir en la parla habitual, fins i tot entre les persones del món rural, llevat que ho facen en referència al sistema de reg, tot reduint significativament la variació lèxica habitual en altres èpoques (gual, palafanga, alter). D'altra banda, cal destacar que malgrat la castellanització dels organismes encarregats del sistema de reg i dels seus dirigents, especialment en el segle xx, i de les publicacions en què consta el nom de les séquies, el valencià ha resistit dignament, no sense algunes greus incorreccions, les formes pròpies autòctones que han donat nom, de bell antuvi, a les nostres séquies. Amb tot, fora aconsellable que el Sindicat de Regs de Borriana fera una aposta decidida per la normativització i la normalització de la hidronímia a Borriana, això sí, tot respectant l'origen, la tradició i la llengua pròpia dels borrianencs i de la Plana davant la influència i la transgressió del castellà.

Finalment, volem destacar d'aquest treball el que significa com a aportació del nostre gra d'arena als estudis locals. Conèixer els orígens i la història més pròxima a nosaltres és posar en valor el nostre patrimoni, acostar la nostra forma de ser i de viure als borrianencs d'avui i de demà. La globalització no té sentit sense la identitat pròpia i el fet diferencial dels pobles, tots som iguals perquè tots som diferents, i per a conèixer-nos a nosaltres mateixos hem de conèixer tot allò que és nostre $\mathrm{i}$ que ens ha fet ser com som. Si nosaltres no defensem el nostre patrimoni, ningú no ho farà per nosaltres. 


\section{Glossari}

En aquest apartat hem seleccionat un conjunt de paraules relacionades amb els noms comuns i els noms propis de les séquies, a més d'incloure'n d'altres que ens ajudaran a descobrir el sentit d'alguns topònims que fan referència a partides del terme, però que també s'empren en els hidrònims del terme de Borriana. També hem inclòs paraules tradicionals del camp semàntic de l'agricultura que hem emprat en aquest article.

Hem fet servir tres diccionaris per les seues característiques, dos de normatius i un de descriptiu, i hem seleccionat les definicions relacionades amb el context agrícola i el reg, o bé, aquell sentit més aclaridor de l'ús d'aquesta paraula en el nostre context. Els diccionaris seleccionats han estat el Diccionari Normatiu Valencià (DNV), de l'Acadèmia Valenciana de la Llengua, el Diccionari de l'Institut d'Estudis Catalans (DIEC2), normatiu, i el Diccionari CatalàValencià-Balear (DCVB), descriptiu, de mossèn Antoni Maria Alcover i Francesc de Borja Moll.

En les entrades en què falta algun dels tres diccionaris és perquè el diccionari no inclou l'entrada o perquè les definicions que hi apareixen no aporten cap informació per al significat de la paraula en el context d'aquest treball.

\section{almenara [de l'àrab al-manāra]}

- f. AGR. Forat i comporta d'una séquia mare que s'obri per a amollar l'aigua i canalitzar-la en la direcció adient per a distribuir les tandes de reg. / $f$. AGR. Comporta per on amollen l'aigua sobrant del reg retornant-la al riu o a la séquia mare. // f. AGR. Caseta tancada que protegix la comporta d'una séquia. DNV

alter [del llatí altarium, 'cosa alta']

$-m$. altet. $m$. Elevació poc pronunciada del terreny. DNV

$-m$. Elevació petita del terreny. DCVB

assut [de l'àrab as-sudd]

$-m$. OBR. PÚBL. Presa de poca alçària que es fa en rius i en rierols per a detindre les aigües i fer-ne pujar el nivell per tal de derivar-les a una séquia. // m. HIDROL. Embassament de l'aigua d'un corrent. DNV

$-m$. [LC] [OP] Resclosa feta en els rius que permet el sobreeiximent sense erosió al peu de la resclosa. Home roig i gos pelut, a l'assut! DIEC2

$-m$. Mur de contenció que atura o desvia l'aigua d'un riu per aprofitar-la en l'agricultura o en la indústria. DCVB

bota [del llatí bŭtte]

- f. CONSTR. Cisterna. $f$. CONSTR. Depòsit, sovint subterrani, on s'arreplega i es conserva potable l'aigua de pluja. DNV

$-f$. [LC] [AGA] [IMF] [AGF] Recipient de fusta més llarg que ample, de secció transversal aproximadament circular, major en el centre que en els extrems... DIEC2

- tr. Passar per damunt una cosa amb un moviment brusc d'elevació i successiva caiguda. // $f$. Recipient de fusta de forma aproximadament cilíndrica, amb les bases formades per dues posts circulars... DCVB 
braç [del llatí brachŭum]

$-m$. AGR. Canal per al reg, sequieta. DNV

$-m$. [LC] [GL] braç de riu Part d'un riu que se separa del curs principal. DIEC2

$-m$. Corrent d'aigua que es deriva d'un altre que duu direcció diferent. «Braç de riu», «braç de séquia», etc. DCVB

braça [del llatí brach̆̌a]

- braça reial: mida superficial agrària usada en algunes localitats de la comarca de Castelló de la Plana, equivalent a 4'155 metres quadrats i corresponent a 81 pams quadrats valencians. DCVB

braçal [del llatí brachíâle, 'propi del braç']

$-m$. AGR. Braç de riu o ramal de séquia. DNV

$-m$. [LC] [AGA] Braç de riu, ramal de séquia. DIEC2

$-m$. Rec que condueix l'aigua de la sèquia directament al camp que s'ha de regar (Pla d'Urgell, Horta de València, Gandia, Xàtiva). DCVB

bracet [diminutiu de braç]

No té cap definició relacionada amb el reg en cap dels tres diccionaris, raó per la qual cal considerar-lo un diminutiu de braç (vegeu braç).

cabeç [del llatí capǔť̌um]

$-m$. GEOL. Tossal amb el cim arredonit. DNV

$-m$. Part més elevada d'un terreny rost, d'una costa. DCVB

cabeçol [derivat de cabeç]

- m. GEOL. Cabeç de poca alçària. Camí del Cabeçol. DNV

$-m$. Pujolet, coll de muntanya. DCVB

caixer [derivat de caixa < capsa]

$-m$. AGR. Paret lateral d'una séquia. // m. AGR. Espai comprés entre les dos parets laterals que formen una séquia. DNV

$-m$. [LC] Llit d'un riu, d'un barranc, d'una séquia. DIEC2

$-m$. Llit d'un riu $/ / m$. Espai comprès entre els dos marges d'una sèquia $/ / m$. Banda $o$ coster lateral d'una sèquia. DCVB

canal [del llatí canāle]

- m. OBR. PÚBL. Obra destinada a conduir fluxos d'aigua procedents de rius, de torrents, de llacs naturals i artificials o d'aigües subterrànies. Un canal de reg. DNV

$-m$. [AGA] [LC] [OP] Construcció destinada a derivar l'aigua de rius, torrents, etc., amb finalitats de regatge i industrials. El canal de la Infanta. DIEC2

$-\mathrm{m}$. Conducte llarguer, amb la concavitat generalment descoberta, que serveix per dur l'aigua o altre líquid d'una part a l'altra. DCVB 
comporta [derivació: prefix com- porta]

$-f$. OBR. PÚBL. Element d'obturació movible que s'utilitza en els aprofitaments hidràulics per a impedir o regular el pas de l'aigua per un conducte. DNV

$-f$. [LC] [OP] Porta, generalment metàl-lica, emprada per a graduar o impedir el pas de l'aigua en una resclosa, un dic o un rec. DIEC2

$-f$. Porta practicada a una resclosa o altre conducte d'aigua, i que serveix per a impedir o graduar el pas d'aquesta. DCVB

comú [del llatí commūne]

- adj. Compartit per dos o més al mateix temps. DNV

- adj. [LC] Compartit per dos o més a la vegada.

- adj. i subst. m. if. Compartit per dos o més a la vegada. DCVB

derramador [derivació: sufix derramar-ador]

$-m$. AGR. Sequiol que servix per a arreplegar aigua d'una séquia més gran, especialment quan s'embossa. DNV

desaigüe [derivació: prefix des-aigua]

- m. CONSTR. Conducte o canal per on s'escola l'aigua bruta o de pluja. El desaigüe del terrat. // m. GEOGR. Emissari temporal d'un curs d'aigua subterrani. DNV

estany [del llatí stagnu]

$-m$. GEOL. Massa d'aigua de poca extensió, acumulada en una depressió del terreny. DNV

- $m$. [LC] [GG] [GL] Massa d'aigua relativament poc extensa dipositada en una depressió del terreny. DIEC2

$-m$. Massa considerable d'aigua dipositada en una depressió del terreny. DCVB

fanecada [derivat de faneca]

- f. METROL./AGR. Mesura superficial agrària corresponent a la superfície que es pot sembrar amb una faneca de gra, equivalent a 831,096 $\mathrm{m} 2$, aproximadament la dotzena part d'una hectàrea. DNV

$-f$. [AGA] [FIM] [LC] Mesura superficial agrària equivalent a l'extensió de terreny que es pot sembrar amb una faneca de gra. DIEC2

$-f$. Extensió de terra que es calcula que es pot sembrar amb una faneca de gra; conté quatre quartons i és la dotzena part d'una hectàrea. Sis fanecades fan una cafissada, i 36 fanecades equivalen a una jovada. DCVB

fillola [del llatí fìliŏla, 'filleta']

- $f$. Camí, séquia o fil conductor que arranca o naix d'un camí, d'una séquia o d'un fil conductor principal. DNV

$-m$. [LC] Camí, fil conductor, rec, etc., que arrenca o neix d'un de principal. DIEC2

$-f$. Sèquia secundària que, partint de la sèquia mare, porta l'aigua a un tros de terra desviat d'aquella. DCVB 
filloleta [diminutiu de fillola]

- doble diminutiu que fa referència a la grandària o a la jerarquia. Es tracta d'una séquia que arranca o naix d'una fillola, o bé, una fillola menuda en relació a les altres filloles.

\section{forca [del llatí fürca]}

$-f$. AGR. Instrument format per un pal amb dos o més puntes o branques en un extrem que s'utilitza per a alçar, regirar o carregar la palla, l'herba o el fem. // $f$. Aparell format per una barra horitzontal sostinguda per un o dos pals verticals, de la qual penja la corda que servix per a executar els condemnats a morir penjats. El van condemnar a morir en la forca. $\mathrm{DNV}$

$-f$. [LC] [AGA] Pal amb dues o més puntes o branques en un extrem que serveix per a regirar, apilotar, palla, fems, etc., agafar i carregar garbes, feixos. Forca de girar. Forca de ventar. $/ / f$. $[\mathrm{LC}][\mathrm{DR}]$ Aparell format per una barra horitzontal sostinguda per un o dos pals verticals, de la qual penja la corda que serveix per a executar els condemnats a morir penjats. DIEC2

$-f$. Instrument format per un pal de fusta acabat per un extrem en dues o més puntes, que serveix per a alçar o regirar la palla, l'herba, etc. // $f$. Instrument de suplici, format per un o dos pals plantats en terra i un altre entravessat a la part superior, en el qual són penjats els reus condemnats a morir ofegats per suspensió. DCVB

forques [plural de forca]

- nom d'un poble en el Rosselló (cantó de Tuir), de diferents caserius (en els termes municipals de Culla, de Cella, etc.), partides de terra (en terme de Sta. Col. de Q., de Sarral, etc.) i muntanyes (Maestrat, Vall d'Hostoles, etc.). DCVB

gola [del llatí gŭla]

$-f$. AGR. Extremitat d'una séquia mare que desemboca en el mar // $f$. $A G R$. Séquia que arreplega aigua sobrant i se l'emporta a una altra banda. DNV

$-f$. [GG] Pas estret d'entrada a certs indrets. La gola del port, d'un riu. La gola de l'avenc, de l'abisme. DIEC2

$-f$. Obertura i passatge d'entrada. «La gola del port»; «la gola d'un riu»; «la gola d'un pou», «d'una séquia», etc. // $f$. Especialment: a) Extremitat d'una sèquia mare que desemboca a la mar (Castelló de la Plana).-b) Sèquia que recull aigua sobrera i se l'enduu a una altra banda (Pego). DCVB

\section{gual [del llatí *vadale]}

$-m$. Lloc d'un riu amb el fons ferm, pla i poc profund, per on es pot passar caminant, cavalcant o amb algun vehicle. // m. CONSTR./OBR. PÚBL. Depressió feta en una calçada, una carretera o un carrer, per a conduir l'aigua de pluja. DNV

$-m$. [GL] [LC] [GG] Indret d'un riu en què l'aigua és prou baixa i el fons prou bo perquè s'hi pugui passar caminant. Passar un riu a gual. // m. [OP] [AQ] Depressió feta a la calçada, d'una carretera o d'un carrer, per a conduir l'aigua de pluja. DIEC2

$-m$. Indret d'un riu en què hi ha poca fondària d'aigua i el fons és prou bo perquè hi puguin passar caminant. DCVB 
jussà -ana [derivat de $j u s$, 'cap avall']

- adj. Inferior. adj. Situat més avall, més a prop del fons o de la base d'alguna cosa. DNV

- adj. [LC] Que està situat més baix que un altre. DIEC2

- adj. ant. Inferior; que està sota. DCVB

marge [del llatí margĭne]

$-m$. Vora, límit d'una extensió superficial, especialment quan fa desnivell o forma escaló. DNV

$-m$. [LC] Vora, especialment d'un terreny que forma graó. DIEC2

$-m$. Vora, especialment d'un terreny o altra cosa que forma graó o desnivell. DCVB

Matella [derivat de mata]

- b) Partida de terra en l'horta de Borriana. DCVB

Millars [del llatí mīliāres, 'camps de mill']

- m. AGR. Camp sembrat de mill. DNV

$-m$. [AGA] Camp de mill.

- topon. Riu que neix en la serra de Gúdar (prov. de Terol) i recorre la província de Castelló. DCVB

moleta [diminutiu de mola]

$-f$. $A G R$. Estesa de garbes que es disposen damunt de l'era preparades per a ser batudes. DNV

$-f$. [IMI] [LC] Quantitat d'aigua necessària per a moure una mola de molí. DIEC2

$-f$. Estesa de garbes damunt l'era preparades per a esser batudes (val.) DCVB

pantà [de l'italià pantano]

$-m . O B R$. $P U ́ B L$. Depòsit artificial d'aigua de grans dimensions que es forma interrompent el curs d'un riu o fent créixer un llac per mitjà d'una gran resclosa. $/ / \mathrm{m}$. GEOL. Sector de terreny fangós i de vegetació abundant on s'estanquen les aigües de manera natural. DNV $-m$. [LC] [OP] [GL] Dipòsit d'aigua artificial de grans dimensions que es forma interrompent el curs d'un riu o fent créixer un llac per mitjà d'una gran resclosa. DIEC2

$-m$. Gran dipòsit d'aigua format tancant amb un mur la boca d'una vall. // $m$. Gran massa d'aigua embassada i fangosa. DCVB

pantanet [diminutiu de pantà] (vegeu pantà)

palafanga [composició: pala - fang]

- Sèquia o braçal profund per a escórrer l'aigua d'una terra humida o patamoll. DCVB

parada [derivat de parar]

$-f$. AGR. Massa de terra, brossa, posts o pedra amb què es tapa la boca d'un rec perquè l'aigua es detinga o es desvie. DNV

$-f$. [LC] Acció de parar o de parar-se. DIEC2

$-f$. Acció i efecte d'aturar, de suspendre el moviment o l'activitat. DCVB 
partidor [derivat de partir amb el sufix -dor]

- m. AGR. Obra hidràulica que per mitjà de comportes separa l'aigua d'un canal en dos o més corrents. // m. AGR. Lloc on es fa esta separació de l'aigua. DNV

$-m$. [LC] Instrument o dispositiu que serveix per a partir o repartir. Un partidor de cabells. Un partidor d'aigües. DIEC2

$-m$. Cosa que serveix per a partir, per a distribuir. Especialment: e) Dispositiu per a separar l'aigua d'un canal en dos corrents (Horta de Val.). DCVB

portell [diminutiu de porta]

$-m$. CONSTR. Obertura estreta deixada en un marge o en un tancat per a permetre el pas. DNV

$-m$. [LC] [AQ] Pas d'entrada en un marge o en una tanca, que permet just el pas d'un carro. DIEC2

$-m$. Esvoranc, solució de continuïtat produïda en un marge o paret per la força de l'aigua o per un altre accident. // Obertura estreta deixada en una paret o marge per a permetre el pas a homes o a bestiar. DCVB

rajolí [diminutiu de raig]

$-m$. Raig molt prim d'un líquid. DNV

$-m$. [LC] Raig molt prim d'un líquid.

$-m$. Raig prim // Rajolí: topon. a) Sèquia del Rajolí: nom d'una sèquia situada prop de Borriana (Cast.). // Intens. dobles diminutius: rajolinet. DCVB

rec [preromà *rĕcu]

$-m$. AGR. Séquia. DNV

$-m$. [LC] [AGA] [GG] Canal per on es condueixen les aigües per a regar. DIEC2

$-m$. Sèquia, cavitat oberta en terra per a conduir l'aigua per a regar // Solc fet a terra per plantar-hi hortalisses. DCVB

reg [derivat de regar]

$-m$. AGR. Acció de fornir aigua a les terres. DNV

$-m$. [LC] [AGA] Acció de fornir aigua a les terres. Terres de bon reg. DNV

$-m$. Acció de regar DCVB

resclosa [del llatí vg. *resclausa (var. de reclausa, 'tancada')]

$-f$. OBR. PÚBL. Paret que es construïx transversalment en un curs d'aigua per a fer que puge de nivell i desviar-la fora del seu llit. DNV

$-f$. [LC] [OP] Paret que es fa a través d'un riu, d'un canal, etc., per alçar el nivell de l'aigua i derivar-la fora del seu llit cap a un molí, un rec, etc. DIEC2

- $f$. Paret, palissada o munt de pedrenys colllocat a través d'un riu, canal o altre corrent d'aigua, per a alçar el nivell d'aquesta i desviar-la del seu llit cap a un rec, molí, etc. DCVB

séquia [de l'àrab sāqiya]

$-f$. AGR. Canal excavat en terra per on es conduïx l'aigua d'un riu o torrent per a regar camps. DNV 
- f. [LC] [AGA] [GG] Canal d'irrigació. // [AGA] [GG] séquia fillola Séquia secundària.

// [AGA] [GG] séquia major [o séquia mare] Séquia principal. DIEC2

- Excavació llarga i estreta, sovint revestida de pedra o de rajoles, que serveix per a conduir aigua d'un riu o torrent, sia per a abastir poblacions, sia per a regar, per a moure molins, etc. // Sèquia mare o sèquia major: la sèquia més ampla, que pren l'aigua directament del riu i la transmet a les sequioles per repartir-la als terrenys de regadiu. Sèquia fillola: sèquia secundària, que pren l'aigua de la sèquia mare.

sequiol [diminutiu de séquia]

$-m$. AGR. Canal secundari, en un sistema de reg. DNV

$-m$. [LC] sequiola: $f$. [LC] [AGA] Séquia secundària. DIEC2

$-m$. sequió: $m$. Sèquia molt estreta (val., mall.) DCVB

sitjar [nom col-lectiu derivat de sitja]

$-m$. Lloc on hi ha sitges. DNV

$-m$. [LC] Lloc on hi ha sitges. DIEC2

$-m$. Lloc on hi ha moltes sitges de blat. DCVB

sobirà -ana [del llatí *supĕriānu, 'el de més amunt']

- adj. [ant.] Que està situat més alt que un altre, en un nivell superior. DNV

- adj. [LC] Que està situat més alt que un altre, en un nivell superior. DIEC2

- adj. Situat més amunt que un altre (per oposició a jussà)

tanda [probablement de l'àrab damdah]

$-f$. $A G R$. Torn de regada que toca a cada participant d'un dret d'usar l'aigua d'una séquia o d'un riu segons la reglamentació establida. / $f$. AGR. Quantitat que ha de pagar un propietari de terra per tindre dret a rec. Han vingut a cobrar la tanda. DNV

- f. [LC] [ECT] En una sèrie de coses, d'accions, etc., que alternen, que se succeeixen, el moment d'acomplir cadascuna. Arribar a algú la seva tanda. Demanar tanda. Donar tanda. DIEC2

- La part de temps que toca de regada a cada participant d'un dret d'usar l'aigua d'una sèquia o d'un ríu segons la reglamentació establerta. // Mida de la fondària d'un riu; posició determinada per a amidar o assenyalar la fondària de les aigües (Tortosa). DCVB

terç [del llatí těrtüu]

$-m$. Part d'una cosa dividida en tres parts iguals. Un terç, 1/3. Dos terços, 2/3. DNV

$-m$. [LC] [MT] Part d'una cosa dividida en tres parts iguals. Un terç, 1/3. Dos terços, 2/3. DIEC2

$-m$. Cadascuna de les tres parts iguals en què es divideix una cosa. DCVB

tros [origen incert]

$-m$. AGR. Peça de terra, camp de conreu. DNV

$-m$. [LC] [AGA] Peça de terra que posseeix algú. DIEC2

$-m$. Porció de terreny de conreu que algú posseeix DCVB 
ull [del llatí $\breve{o c} \breve{l} l u s]$

$-m$. AGR./HIDROL. Ullal 1 i 2 . DNV

$-m$. [LC] [GL] Sot on neix un curs d'aigua. L'ull d'una font. Ull de Ter, de Garona. DIEC2 $-m$. Forat per on surt l'aigua d'un molí o per on passa l'aigua d'una sèquia. // Cavitat d'on brolla l'aigua d'una font, d'un riu, d'un corrent qualsevol. DCVB

ullal [derivat d'ull amb el sufix -al]

$-m$. AGR. Obertura per on ix l'aigua d'un molí o per on passa l'aigua d'una séquia. // $m$. HIDROL. Clot on naix un riu, cavitat d'on brolla l'aigua d'una font. DNV

$-m$. [GL] Clot, forat, per on surt aigua. // $m$. [GL] Font subaquàtica, sobretot en espais d'aiguamoll o albuferes. DIEC2

- Lloc on brolla aigua subterrània. // Clot profund per on es precipita l'aigua de la mar, d'un riu, etc., formant remolí DCVB

ullet [diminutiu d'ull]

No té cap definició relacionada amb el sistema de reg en cap dels tres diccionaris, raó per la qual cal considerar-lo un diminutiu d'ull (vegeu ull o ullal).

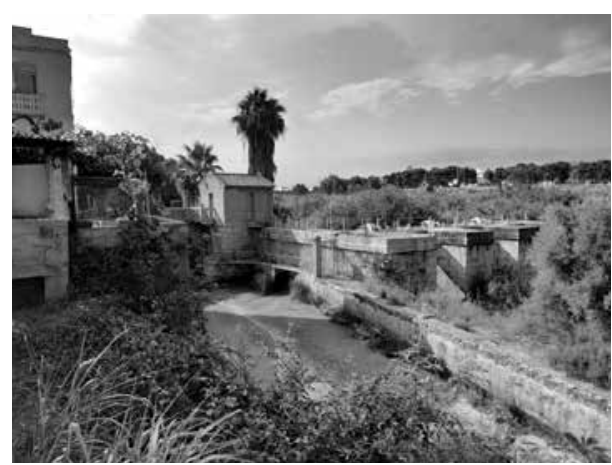

L'assut de Borriana al riu Millars.

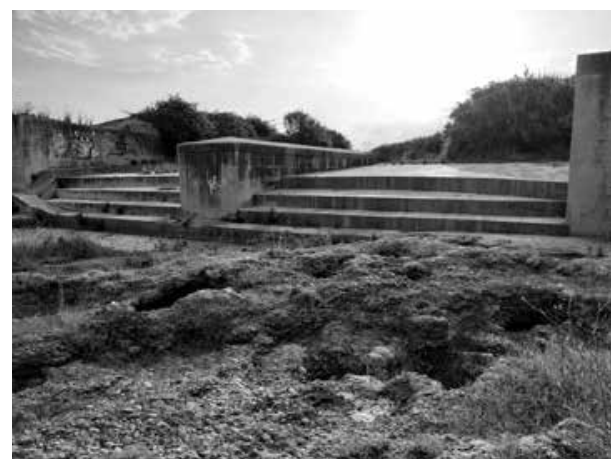

La Bota, pas soterrat de la séquia Sobirana pel riu Sec.

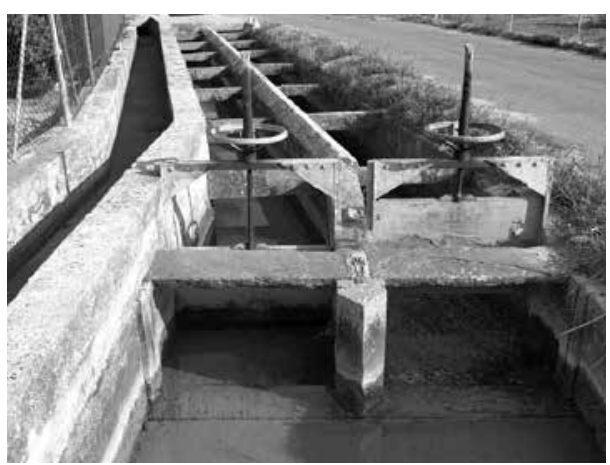

Partidor Major de les séquies Jussana i Sobirana, $i$ comportes de la séquia Sobirana i la séquia de Nules.

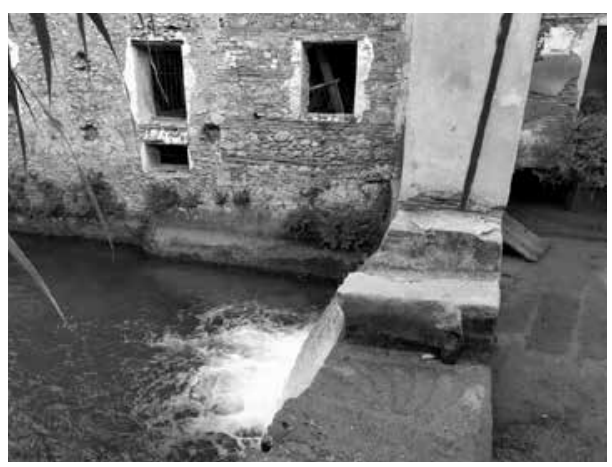

Salt de la séquia Sobirana pel Molí de l’arròs. 


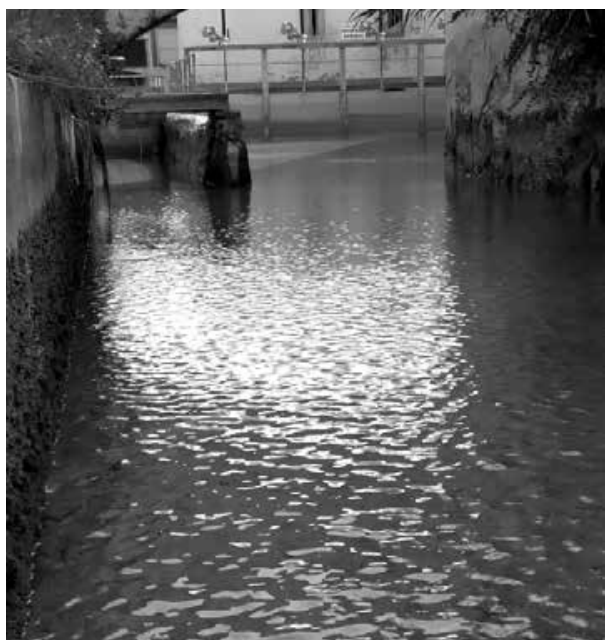

Partidor Major de les séquies Jussana i Sobirana, $i$ comportes de la séquia Sobirana i la séquia de Nules.

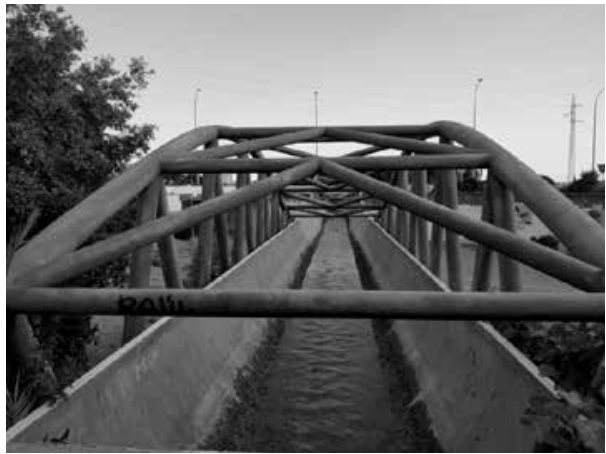

La séquia Sobirana quan travessa el camí d'Onda.

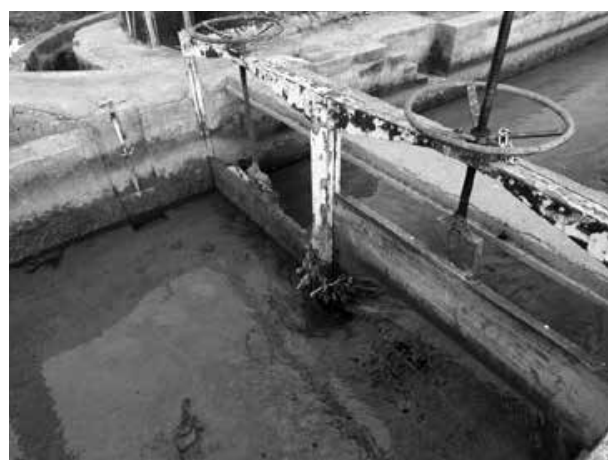

Parada per a abastir un ull.

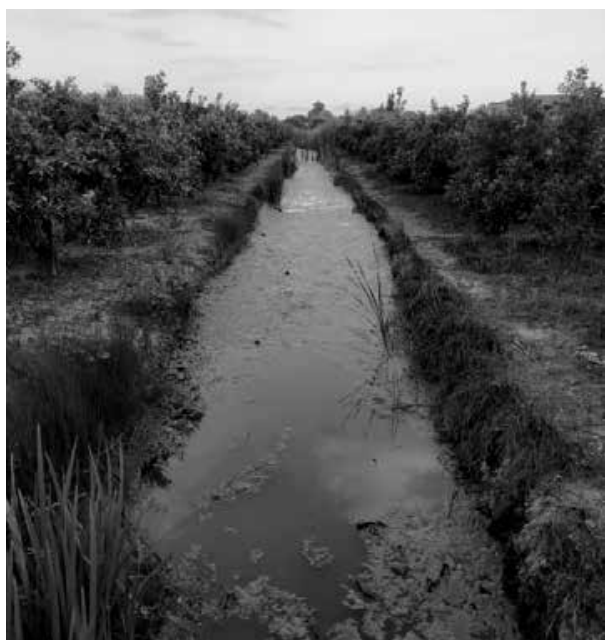

Sequiol a la marjal de Borriana.

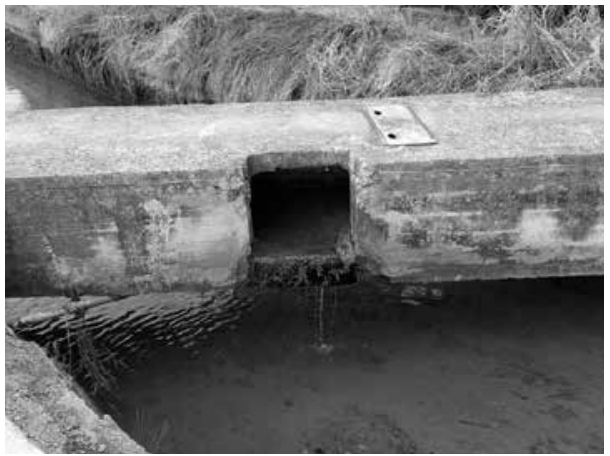

Derramador. 


\section{BIBLIOGRAFIA}

Acadèmia Valenciana de la Llengua (2014): Diccionari Normatiu Valencià. València, AVL. [consulta en línia] <http://www.avl.gva.es/lexicval/>

Alcover, A.M. i F.B. Moll (1930-1962): Diccionari Català Valencià Balear. Mallorca, Moll. [consulta en línia] <https://devb.iec.cat/>

Garrido, S. i M. Vicent (2010): La Comunitat de Regants de Burriana. Borriana, Magnífic Ajuntament de Borriana i Comunitat de Regants de Borriana.

Institut d'Estudis Catalans (1995): Diccionari de la llengua catalana de l'IEC. Barcelona IEC. [consulta en línia] <https://dlc.iec.cat/>

Mesado Oliver, N., ed. (1987-1991): Burriana en su Historia. Borriana, Magnífic Ajuntament de Borriana, vol. I i II.

Roca i Alcaide, F. (1932): Historia de Burriana. Castelló, Armengot.

\section{BIONOTA}

Joan Ramon Monferrer Daudí (Borriana, 1962) Filòleg i professor del Departament de Pedagogia i Didàctica de les Ciències Socials, la Llengua i la Literatura a la Universitat Jaume I (UJI), Màster universitari en Comunicació Intercultural i Ensenyament de Llengües, director de la UEM (Unitat d'Ensenyament Multilingüe) de l'UJI, és membre del Consell Acadèmic de la Fundació Càtedra Enric Soler i Godes. A més, és funcionari de carrera, des de 1988, i catedràtic del cos del professorat d'escoles oficials d'idiomes (EOI). Ha estat vicedirector (1990-93 i 2016-18) i director (1993-2005) de l'EOI de Castelló, i des de 2018 és director de l'EOI Plana Baixa. La seua tasca investigadora principal se centra en l'ensenyament i l'aprenentatge de llengües. És coautor del Portfolio Europeu de les Llengües en format electrònic (ePel+14) del Ministeri d'Educació, acreditat pel Consell d'Europa amb el núm. 105/2010. Ha participat en l'elaboració dels currículums de la JQCV adaptats al MECR, en 2008 i en 2016, també ho ha fet en els currículums d'EOI del Ministeri d'Educació en 2006 i en els de les EOI de Generalitat Valenciana en 2018. Actualment, és tinent d'alcalde i regidor d'Educació, Comunicació i Polítiques Actives d'Ocupació de l'Ajuntament de Borriana. 